\title{
Disaster E-Health Framework for Community Resilience
}

\author{
Tony Norris \\ Department of Computer Science \\ Auckland University of Technology \\ tony.norris@aut.ac.nz \\ Santiago Martinez \\ Department of Health and Nursing Science \\ University of Agder \\ santiago.martinez@uia.no
}

\author{
Jose J. Gonzalez \\ Centre for Integrated Emergency Management \\ University of Agder \\ josejg@uia.no \\ Dave Parry \\ Department of Computer Science \\ Auckland University of Technology \\ dave.parry@aut.ac.nz
}

\begin{abstract}
Disaster management and the health sector ought to be natural allies, but there are few examples of the collaborative planning and application of disaster healthcare involving emergency managers and care practitioners. The different origins, culture, and priorities of the various agencies tasked with disaster healthcare mean that communication and coordination between them is often lacking, leading to delayed, sub-standard, or inappropriate care for disaster victims. The potential of the new e-health technologies, such as the electronic health record, telehealth and mobile health, that are revolutionizing non-disaster healthcare, is also not being realised. These circumstances have led to an international project to develop a disaster e-health framework that can inform national disaster and health strategies. This paper describes this project and its extension to embrace community resilience that strengthens preparedness, safeguards life during the disaster phase, and assists long-term recovery to preserve the health and basic values of citizens.
\end{abstract}

\section{Introduction}

A survey of recent disasters, whether they are natural catastrophes, human technological errors, epidemics, wars, or terrorist activities, reveals their destructive impact on infrastructure and economies, and the grim costs of individual lives and misery [1, 2]. A perceived increase in the incidence of these events has motivated the development of disaster management as a methodical discipline to respond to and mitigate their often-terrible effects. Whilst the media predictably focus on the immediate aftermath of a catastrophe, disaster management tackles issues at all stages of the disaster cycle; mitigation, preparedness, response, and recovery [3].

In a major disaster, there are invariably human casualties who need rapid treatment for trauma and the specialised field of disaster medicine has evolved for this purpose [4]. Disaster medicine applies public health and specialist tools to define clinical protocols in a disaster, and to teach the competencies required by clinical personnel [5]. The health consequences of such events, initially exhibited as fatalities and injuries, are frequently encountered years later as chronic and mental illnesses [6].

Whilst disaster management is beginning to deploy information and communication technologies (ICTs) to good effect $[7,8]$, there is little systematic use of modern e-health tools in disaster medicine $[9,10]$. These technologies, such as the electronic health record (EHR), telehealth, decision support systems, data analytics, RFID, Internet of Things, cloud computing, and social media etc., are revolutionising the planning and delivery of mainstream healthcare [11]. They can make health information and healthrelated services available anytime, anywhere, automate workflows, and provide seamless care for immediate intervention or longer-term treatment. They also 'democratise' healthcare by encouraging the active participation of the consumer in the care process. Crucially, however, disaster medicine clinicians are seldom trained to be aware of these technologies, let alone to acquire competency in their use [12].

In fact, disaster management and the wellestablished discipline of disaster medicine have different origins, development, and priorities so that communication and coordination across these disciplines during disasters is often lacking, leading to delayed, sub-standard, inappropriate, or even unavailable care. This concern has prompted [12] to comment that, "Emergency management and the health sector are natural allies that have, seemingly, only recently begun to recognize each other".

These considerations have led to an international project to develop a new paradigm of Disaster e-health - 'the application of e-health technologies to assist the prognosis and treatment of the sick and injured in a disaster, and to support appropriate care in the post- 
disaster situation. Disaster e-Health (DEH) can be thought of as a domain at the intersection of three constituent fields; disaster management, disaster medicine, and e-health.

The ISCRAM community and ISCRAM's annual international conferences created bonds between Auckland University of Technology, New Zealand, and the University of Agder Norway. Both institutions conduct research on health, e-health and disaster management. This led to collaboration between research teams from both institutions to advance disaster e-health as a lever to improve disaster healthcare. The research group expanded quickly to incorporate expertise in information systems from the University of Nebraska, Omaha (UNO), USA, and has grown further to embrace researchers from universities in Canada, Bulgaria, Sweden, and France. The on-going research, referred to as the DEH project, has succeeded in scoping the disaster e-health domain and developing key research topics such as interagency communication, scenarios for DEH applications, and education [13-15].

The DEH project has received grants that have led to the appointment of two PhD students at AUT. The research has succeeded in scoping the disaster e-health domain and developing key topics such as interagency communication, scenarios for DEH applications, and education [13-15]. The grants have also been used to run international workshops in Norway, the USA, and New Zealand as well as at the recent ISCRAM 2017 conference in France. The goal of these workshops has been to develop a road map for $\mathrm{DEH}$ that accelerates its development and sets the domain on a path to becoming a vital and sustainable component of mainstream disaster healthcare [13].

Running in parallel with the DEH project, a European (EU) Horizon 2020 research project, with nine different countries involving cities and universities throughout Europe, has been looking at crisis and disaster resilience with a view to developing a holistic approach to resilience that integrates the many perspectives, including healthcare, that need to be considered when an emergency or disaster occurs [16].

The remainder of this paper explores the relationship between $\mathrm{DEH}$ and resilience and discusses the extension of the $\mathrm{DEH}$ research to the design and application of a DEH Resilience Framework for disaster preparedness, response, and recovery at a community level.

\section{Community Resilience and DEH}

\subsection{Community Resilience}

Community resilience, the sustained ability of a community to withstand and recover from disasters, has become a key policy issue for many countries in recent years due to the increasing incidence of manmade tragedies such as terrorism, wars, chemical hazards, and infrastructure failure, as well as epidemics, and disasters exemplified by floods, earthquakes, and tsunamis etc [17]. These events have led to strategic initiatives at local and national levels [18-20] that recognise the importance of mitigation, preparedness, and long-term recovery alongside the immediate, essential response that follows a disaster, as critical components of resilience.

Disasters are highly complex incidents. Minimising their impact clearly demands multifaceted, holistic approaches that can be applied generally at the pre-event, response, and post-event phases. However, whilst there is consensus on the need to incorporate community resilience at all levels, there is less clarity on the resilience-building process [18] and the 'levers' for action that enable communities to recover quickly.

This holistic approach is especially important in the context of health-related resilience where effective care in and after a disaster is grounded in public health promotion, planning, and delivery [12] with an emphasis on preventative care, disaster medicine, emergency management, and community capacity building.

There is therefore an imperative to develop a framework for disaster health that integrates the principles and practice of the contributing domains and combines them holistically to enhance community resilience. Research directed to this goal has begun to appear emphasising mainly practical aspects [21] but also addressing the need for a theoretical foundation and generic principles [22]. As mentioned previously, this framework should recognize the potential of cutting-edge e-health technologies [11] for disaster health.

This framework must enhance general community awareness and domain communication and, more specifically, leverage fixed and mobile e-health technologies to share information, including reports from crowd sourcing and trusted social media sources, and to use apps to facilitate self-reliance when clinical care and resources are scarce. The framework should focus on local communities and their interaction with other agencies and be sensitive to cultural differences and the needs of disadvantaged groups including migrants from disaster-affected countries.

The following sections present a brief survey of current issues and research in community resilience and disaster-related health to provide the background 
for a more focused discussion of the approach to developing a DEH Resilience Framework.

\subsection{Current Issues and Research in General Community Resilience}

The definition of community resilience given in $\S 2.1$ is concise and it captures neatly the essence and purpose of the concept. However, it conveys little of its complexity. Meaningful discussion of resilience requires knowledge of the scope of the community [23]. For example, a household, a town, a region, or a country, etc., may have quite different goals for resilience contingent upon their size, scale, and population density, as may similar sized communities troubled by different risks due to their climates or locations (vulnerability) [23]. Rural populations [24] might be more self-sufficient than large cities dependent on central services such as waste disposal, or they might not have the conurbation's resources to respond quickly when a disaster strikes. Neither does the definition tell us how to deal with conflicts that might occur between residential and business communities with different priorities [25].

Similar difficulties arise when we consider the 'resilience' component of community resilience. Given the wide scope of communities, and their different capacities to withstand and respond to crises, just how do we assess and measure resilience [26-28] so that we can establish a base line and monitor improvement? What are the criteria or 'levers' for improvement [18]? How do we go about improving community resilience [28]?

Straddling these complexities are two overarching concerns. The first pertains to the realisation that a state of resilience is not a static equilibrium returned to after the perturbation generated by some crisis [29]. Communities evolve and adapt, and improved resilience adds to the process of change. The second concern is the observation, as mentioned already, that any attempt to enhance community resilience cannot concentrate on independent parameters; it must be multifaceted and holistic [26] and that is difficult to do.

Against this background, it is useful to consider some general approaches to improving community resilience. Early research adopted a quantitative approach typified by the GOAL project [30]. This approach firstly identifies key components that characterise resilience and groups them under themes such as governance, preparedness, and vulnerability that collectively describe the resilience status. A toolkit then uses questionnaires to collect socioeconomic and demographic data on the community, identify vulnerable groups, and gather information on the main hazards and their frequency. These data are analysed using 30 questions that relate to the themes from which the answers generate a numerical resilience score and a baseline that suggests recommendations for improvement. Repeating the process at a later date provides a measure of the progress made.

The Conjoint Community Resiliency Assessment Measure (CCRAM) [31] profiles and predicts community resilience using a more sophisticated version of the GOAL toolkit. The Conjoint Community Resiliency Assessment Measure adopts an iterative process that combines literature reviews, past studies, and Delphi consultations with a multidisciplinary group of content experts. Data are collected and analysed by advanced statistical methods as well as by qualitative methods used in the social sciences reflecting a shift from an essentially quantitative approach to give increased weight to issues of citizen interaction, social capital, and loop learning.

This trend emphasises cultural resources and social networks that involve transactions marked by reciprocity, trust, and cooperation for a common good [32]. The trend is exemplified by the emBRACE framework for Social Learning and Resilience Building [33], arising from a multinational European project in 2015. emBRACE draws on expertise across the research spectrum and is structured in modules that proceed from literature review and data collection, through needs assessment to generate themes, modelling, and case studies, bringing issues together holistically in exchanges with stakeholders, and making policy and practice recommendations.

\subsection{Current Issues and Research in Disaster Health Community Resilience}

For a long time, disaster health was seen simply as an extension of conventional (non-disaster) emergency care and the literature [34, 35] contains multiple complaints that the training of physicians does not prepare them for dealing with disasters and their aftermath. This situation is changing, encouraged by a better understanding of the unique, dynamic circumstances presented by disasters [18, 21, 36, 37].

These studies augment long-standing public health approaches [12, 18, 37] to disaster health preparedness by generating frameworks that engage communities and develop toolkits to collect data that measure resilience and deliver iterative improvements (see §2.2). Chandra et al. [18] and Plough et al. [37] provide a comprehensive survey of the aims and 
features of these frameworks underscoring the premises of connectedness, collaboration, and trust that generate and sustain community resilience. They also draw attention to the plight of disadvantaged communities pointing out that vulnerability to a disaster has a social as well as a geographic dimension since people with mental health or chronic health conditions, disabilities, or extreme poverty are most at risk of poor survival outcomes [38].

In their research, Chandra et al. [18] identify eight levers (cf. themes) including wellness and access to care that improve health-related community resilience. These levers have the advantage that they are familiar to public health practitioners and thus provide a bridge between preparedness and traditional communitybased public health practice. The levers offer an interesting comparison with the CCRAM themes noted above.

Disaster risk reduction [39], the systematic approach to identifying, assessing, and reducing the risks of disaster, is clearly a concept directly related to community resilience and healthcare [40]. Disaster risk reduction is the goal of a general programme promoted by the UN [41], and, in the Sendai Framework [21] adopted by 187 UN member states in 2015, this goal is targeted specifically at disaster health. The aim of SENDAI is to replace a hazard and response-driven approach to disaster management by a risk-driven, holistic alternative that encompasses prevention, recovery, and rehabilitation. SENDAI focuses on priorities (cf. themes - see Table 1) related to understanding and reducing risk that target global disaster health goals including decreases in mortality and health impacts, reductions in the disruption to health services, and increases in the number of countries possessing national and local disaster health strategies [21].

For convenience, the principal themes (levers or priorities) for the community resilience frameworks discussed above are summarised in Table 1. They demonstrate common objectives for creating community resilience but different perspectives on how to achieve it. The DEH Framework will synthesise these approaches and extend them to harness the benefits of e-health.

Table 1: Community Resilience Frameworks: Principal Themes, Levers, or Priorities

\begin{tabular}{|l|l|}
\hline Framework & Principal Themes, Levers, or Priorities \\
\hline GOAL & Governance, risk assessment, education, vulnerability, preparedness, response \\
\hline CCRAM & Leadership, collective efficacy, preparedness, place attachment, trust, social relationship \\
\hline emBRACE & Social learning, trust co-operation, capacities \\
\hline SENDAI & Understanding risk, governance strengthening, investing in risk reduction, preparedness \\
\hline Chandra et al. & Wellness, access, education, engagement, self-sufficiency, partnership, quality, efficiency \\
\hline
\end{tabular}

Community resilience frameworks correctly balance disaster preparedness and rehabilitation against response so that if a community is sufficiently prepared and resilient then there is no disaster. However, there is obviously a crucial role for healthcare in the response phase of a crisis and this care is provided either by public health practitioners, or after specialist training, by disaster medicine specialists (Hogan \& Burstein, 2016).

Disaster medicine is founded on a sound scientific basis and accepted terminology developed over centuries whereas emergency management, the other first responder domain in a disaster, has yet to develop such a foundation. This difference is apparent in the descriptive emphasis of much disaster management research and, as has been mentioned [12], the distinction can also cause territorial defensiveness and leadership issues [42] between disaster medicine and manager personnel, leading to poor inter-agency communication [43-45]. Guidelines and protocols to avoid this circumstance constitute a necessary component of a community resilience framework for disaster health, as are joint educational programmes to encourage shared attitudes and approaches centred on the delivery of care.

\section{Role of E-Health Technologies in Disaster Health Community Resilience}

Information and communication technologies are disrupting both the design and delivery of traditional healthcare [46, 47]. The health applications of these ICTs, designated e-health, are bringing major benefits to both patients and practitioners by developing procedures that address four key metrics of care; quality of treatment, equity of access, costeffectiveness, and safety [11]. E-health technologies, especially the Internet and mobile devices, are changing the very basis of care by empowering patients to be more knowledgeable about their medical conditions, to monitor their own health status, and to 
make better decisions that help them to become active, rather than passive, participants in their own care. Clinicians can engage with patients as informed members of the care team [48, 49] and devise customised treatments using precision medicine techniques[50] made possible by e-health techniques.

E-health technologies [11] such as the electronic health record (EHR), tele- and mobile health, and decision support systems are rapidly becoming part of modern healthcare whilst more recent advances such as big data, cloud computing, the Internet of Things, and social media are promising to revolutionise 21st century medicine [51]. Although there have been adhoc applications of e-health in disaster healthcare, for example, electronic triage and telehealth [15], there has been no systematic application of these techniques and none at all outside of the disaster response phase. As mentioned in section 1, this situation is being remedied by the major international project on disaster e-health $[14,15]$. The continuing study has demonstrated how e-health techniques can be used throughout the disaster cycle, for example, in the allocation of health resources, in the design of plans to increase healthcare preparedness, by the use of the EHR during the disaster response, and by using telehealth to support long-term care in the disaster aftermath.

The planned extension to this work described here is the design for a Disaster E-health (DEH) Framework for community resilience and an operational prototype for its application. This section describes the road map to achieve these outcomes.

The concept of the Framework is centred, as stated above, on a toolkit, derived from community engagement and data collection that describes the disaster e-health resilience of a community and provides guidelines on how to improve it. Here we develop the stages of a road map to translate this concept into a unified DEH Resilience Framework. The research process draws upon previous work but the use of e-health technologies to improve community resilience in healthcare is an entirely new field and the Framework design may change to accommodate the research findings. Details of the road map methodology are described in §4.

The starting point for the roadmap is the definition of an unambiguous terminology accepted and understood by policy makers, managers, community leaders, and members of the public. The lexicon will be based on the UN's Terminology of Disaster Risk Reduction [52] and supplemented or amended by terms invoked in other relevant publications [22], including recent ones that deal with social capital [19, 31] and social learning [33] in community resilience, and terms that are commonly used in e-health [33].

In 2015-2106 Birnbaum et al. published a sequence of papers aimed at establishing a definitive conceptual framework for disaster-related health based on the disaster cycle [22, 40, 53-59]. These papers cover an extensive range of topics from hazard classification, through societal structures such as water, sanitation, and medical care, to risk management, risk reduction, and capacity building. The rigorous approach and arguments presented will inform the design process for the DEH Framework and help to place it on a sound theoretical basis. The papers do not however cover ehealth principles and applications.

Armed with a common language, the roadmap can then proceed to identify key themes of the DEH Resilience Framework and to construct related questions and metrics for the toolkit. To demonstrate the process, Table 2 displays example themes appropriate to the Framework selected from the range shown in Table 1, and related toolkit questions (ehealth related questions are italicised) that help to establish and measure community resilience status and the steps needed to improve it. The themes and questions in Table 2 are chosen purely to illustrate the operation of this core part of the Framework. The envisioned full project will add and refine themes, questions and metrics so that a customised toolkit provides a comprehensive and clearly defined picture of a community's disaster health resilience and how ehealth can best enhance it. 
Table 2: DEH Resilience Framework: Example Themes and Illustrative Toolkit Questions

\begin{tabular}{|c|c|}
\hline Theme & Illustrative Toolkit Questions \\
\hline Community \& engagement & $\begin{array}{l}\text { Is the community leadership committed, effective, and accountable? } \\
\text { Are vulnerable groups represented in community decisions? } \\
\text { Do the e-health and traditional health technologies integrate seamlessly? } \\
\text { Have the privacy, security and ethical aspects of disaster e-health been assessed? }\end{array}$ \\
\hline Knowledge \& education & $\begin{array}{l}\text { How is information on disaster hazards and preparedness disseminated? } \\
\text { Is the DEH Framework sensitive to cultural and indigenous beliefs? } \\
\text { Are there community courses for citizens to understand the benefits of e-health? } \\
\text { How does the community ensure citizens can take advantage of e-health? }\end{array}$ \\
\hline Risk assessment \& management & $\begin{array}{l}\text { Does the community adopt environmental practices that reduce hazard risk? } \\
\text { How does the community ensure continuity of essential services in a disaster? } \\
\text { Is electronic prescribing available to ensure drug continuity in a disaster? } \\
\text { Are EHR systems on line and usable when infrastructure is damaged? }\end{array}$ \\
\hline $\begin{array}{l}\text { Disaster preparedness \& } \\
\text { response }\end{array}$ & $\begin{array}{l}\text { What mechanisms are there to ensure community awareness of disaster } \\
\text { issues? } \\
\text { Is there an operational Early Warning System in the community? } \\
\text { Do emergency managers and disaster medicine specialists communicate } \\
\text { effectively? } \\
\text { Are there community-wide e-health apps that assist self-healthcare in } \\
\text { disasters? }\end{array}$ \\
\hline Disaster rehabilitation & $\begin{array}{l}\text { Is there an understanding of the long-term effects of a disaster on the } \\
\text { community? } \\
\text { What are the rate-determining steps in returning a community to normality? } \\
\text { Are there community telehealth systems to assist citizen rehabilitation at } \\
\text { home? } \\
\text { Does the community have an on-line patient support system? }\end{array}$ \\
\hline
\end{tabular}

Although the benefits of e-health continue to be demonstrated [60], there are also project failures and barriers to adoption. Analysis shows that these episodes are commonly caused, not by deficiencies in the technologies themselves, but by issues such as over-promotion of benefits, previous disappointments, fear of novelty, uncertain commitment, poor motivation, power conflicts, and insufficient capacity to affect and sustain change etc; all concerns that generate resistance to change.

These same causes can easily spoil attempts to improve community resilience in any sphere. They represent a challenge to the success of any novel project, and understanding them and managing change will be important processes in the development and implementation of the DEH Resilience Framework.

\section{Methodologies and Operational Details of the Envisioned Project}

This section provides details of the main toolkit processes needed to implement the proposed framework and improve DEH resilience.
Note that the methods described below are being successfully employed in a major collaboration involving the University of Agder and the municipality of seven European cities, viz. in the EU H2020 Smart Mature Resilience (SMR) project running for three years $1^{\text {st }}$ June $2015-31^{\text {st }}$ May 2018 [16].

Community engagement: The construction of the Framework toolkit depends critically on the composition of the community groups involved and the mode of operation of the information sharing and decision processes that underpin it. Such engagement will be based on a Living Lab facility [61], a holistic concept that aims to generate innovative, user-driven solutions to real-world problems by building upon users' understanding of existing and future needs. The approach attempts to empower citizens, who may have different levels of health literacy, to greater selfreliance supporting them within the community, for example, by appointing a health resilience specialist aware of each citizen's health needs and acting as a need-coverage coordinator and local trusted source goals highly relevant to disaster situations.

The methodology used to establish community (or focus) groups and ensure constructive debate is the 
quadruple helix model [62] that insists on dialogue that involves citizens, industry (including here health and emergency sector organisations), academia, and government. The exchange of views arising from the varying perspectives offered by these associations encourages individual, institutional, and multisectorial, learning, and the collaborative enquiry that is the essence of social learning and adaptability [33].

Data Collection: In the context of the DEH Framework, data collection refers to the literature search, inquiry, observation, and general fact-finding that reveal the socio-economic status, governance, preparedness, and vulnerability of a community and, by extension its resilience to disaster. In assembling the collection (as with community engagement), care is needed to avoid bias, and in particular to ensure that the data represent oft-underprivileged communities such as indigenous peoples, refugees, the elderly and those with disabilities.

Theme definitions: Table 1 includes many of the generic themes relating to community resilience. A glance at the Table exposes overlap between some entries, whereas others, although superficially similar (e.g. partnership, collective efficacy), may have nuanced differences worth retaining in specific circumstances. The toolbox themes used to describe community resilience should therefore be obtained from the community engagement and data collection processes, making them applicable to the particular community and updateable as conditions demand. To ensure that the theme definitions captured in this way form an optimal set, they will be verified in a Delphi study seeking expert opinions from a Panel with the same representation as the community engagement group but with different membership.

Questions: The questions used to ascertain community (disaster e-health) resilience are similarly derived from the engagement and data collection processes, and from the derived themes that they are intended to amplify (see §3). It may help [33] to assign a Likert scale ranging from minimum to maximum resilience to an answer to a question to generate a quantitative measure of resilience. The set of questions (and metrics, see below) will also be subject to Delphi verification.

Metrics: A measure of resilience can be obtained directly as, for example, by determining the number of water purification tablets available in the community per person per day, and comparing it with some accepted norm. A complementary approach is to combine scaled answers to questions to give an overall percentage score that places a community in a resilience category, for example, 0-20\%: minimal resilience, 21-40\%: low resilience, and so on [30]. This approach establishes a baseline that can be used to indicate a community's progress in its efforts to improve its general and disaster e-health resilience.

Guidelines: In the present context, a guideline is a recommendation for an action that improves community resilience. It can be qualitative, e.g. 'provide a telehealth facility that can be made available in the event of a disaster', or quantitative, e.g. 'provide a telehealth facility that can be made available in the event of a disaster and ensure that three doctors and three nurses are on call to offer 24-hour cover when a disaster occurs'. Any community unable to guarantee adequate cover would have a low resilience score. Although some guidelines may appear to be one-off, for example, advice on the range of drugs available for on-line prescribing in an emergency, there will invariably be a need for periodic review.

Education: Informal education, especially between peers, is vital to resilience building and it should occur at every one of the stages described above. However, when the community is missing important knowledge and skills, or there is need for a more comprehensive/structured approach to learning, then formal courses have great value. Often courses are targeted for particular groups but community resilience improvement may be best served by joint courses where groups can learn about one another's needs in a disaster situation. A prime example is the information that should be communicated between disaster managers and disaster clinicians in the response phase of a disaster.

Simulation models encapsulated in Interactive Learning Environments (ILEs) have proven to be successful community education tools in Norwegian municipalities [63]. These are being developed similarly within the H2020 Smart Mature Resilience project [16] and will find application in advancing the DEH Resilience Framework.

Framework Evaluation: As is planned in the SMR project noted above, the disaster e-health framework will be evaluated initially by a formal feedback process (probably a Delphi study) involving practitioners to resolve issues and to ensure compatibility with existing resilience procedures. Further testing will be carried out by designing and running simulation exercises that test the usability and appropriateness of the framework whilst at the same time training participants. The simulations will include scenarios that prepare planners and responders to anticipate circumstances where information is often incomplete such as emergency calls for medical facilities from many sources other than a medical response number or the availability of a database on residents that need regular medication. 


\section{Concluding Remarks}

From an e-health perspective, the involvement of health professionals and patients in the design, development, and evaluation of modern health and welfare systems, and the integration of these systems into existing services and personnel workflows, coupled with the required training needs, present significant challenges for the creation of a disaster ehealth framework for community resilience. Two main reasons sustain the claim: the community perspective that necessarily calls on diversity, the right to universal health and social care; and the long-term perspective of personnel, systems and services not designed to work under disaster conditions. The framework described in this paper recognises that cooperation with responders and decision-makers in municipalities, as well as with stakeholders, is a sine qua non. Steps to launch a research project in cooperation with a major Norwegian municipality have been taken. In Norway where municipalities are responsible for public health services and continuity of critical services. Hence, they cover the roles of both health authorities and disaster managers, which may be part of different organisations elsewhere. Collaboration with municipalities ensures a wide access to professional experience (medical, psychological, risk assessment and mitigation, preparedness, response and recovery as well as relevant stakeholders).

\section{References}

[1] S. Al-Shaqsi, R. Gauld, S. Lovell, D. McBride, A. AlKashmiri, and A. Al-Harthy, "Challenges of the New Zealand Healthcare Disaster Preparedness Prior to the Canterbury Earthquakes: A Qualitative Analysis," The New Zealand Medical Journal (Online), vol. 126, 2013, pp. 9-18.

[2] Centre for Research on the Epidemiology of Disasters, "The Human Cost of Natural Disasters," Accessed on: 31 May 2017. Available: http://emdat.be/human_cost_natdis

[3] C. Warfield, "The Disaster Management Cycle," 2017, Accessed on: 31 May 2017. Available: https://www.gdrc.org/uem/disasters/1-dm_cycle.html

[4] D. E. Hogan and J. L. Burstein, Disaster Medicine, Philadelphia, PA, USA: Lippincott, Williams and Wilkins, 2016.

[5] I. Subbarao et al., "A Consensus-based Educational Framework and Competency Set for the Discipline of Disaster Medicine and Public Health Preparedness," Disaster Medicine and Public Health Preparedness, vol. 2, no. 1, 2008, pp. 57-68.
[6] S. Galea, "The Long-term Health Consequences of Disasters and Mass Traumas," Canadian Medical Association Journal, vol. 176, no. 9, 2007, pp. 1293-1294.

[7] V. Hristidis, S.-C. Chen, T. Li, S. Luis, and Y. Deng, "Survey of Data Management and Analysis in Disaster Situations," Journal of Systems and Software, vol. 83, no. 1, 2010, pp. 1701-1714.

[8] R. R. Rao, J. Eisenberg, and T. Schmitt, "Improving Disaster Management: The Role of IT in Mitigation in Preparedness, Response, and Recovery." Washington D.C., USA: The National Academy Press, 2007.

[9] J. J. James and L. Walsh, "E-health in Preparedness and Response," Disaster Med Public Health Prep, vol. 5, no. 2011, pp. 257-258.

[10] K. Sakanushi et al., "Electronic Triage System for Continuously Monitoring Casualties at Disaster Scenes," $J$ Ambient Intell Human Comput, vol. 4, 2013, pp. 547-558.

[11] E. Coiera, Guide to Health Informatics, 3rd ed. Boca Raton, FL, USA: CRC Press, 2015.

[12] R. A. Bissell, "Public Health and Medicine in Emergency Management (Ch. 16)," in Disciplines, Disasters and Emergency Management : The Convergence and Divergence of Concepts, Issues and Trends from the Research Literature, D. A. McEntire, Ed. Springfield: Charles C Thomas, 2007, pp. 213-223.

[13] R. Abbas, A. C. Norris, D. T. Parry, and S. Madanian, "Disaster E-Health and Interagency Communication in Disaster Healthcare: A Suggested Road Map," Proceedings of the Health Informatics New Zealand (HINZ) Annual Conference, Auckland, 2016.

[14] A. C. Norris and A. Althwab, "The Scope and Development of Disaster E-Health," Proceedings of the Health Informatics New Zealand (HINZ) Annual Conference, Rotorua, 2013.

[15] A. C. Norris, S. Martinez, L. Labaka, S. Madanian, D. T. Parry, and J. J. Gonzalez, "Disaster E-Health: A New Paradigm for Collaborative Healthcare in Disasters," Proceedings of the 12th International Conference on Information Systems for Crisis Response and Management (ISCRAM 2015), Kristiansand, 2015.

[16] Smart Mature Resilience, "Smart Mature Resilience for more resilient cities in Europe," Accessed 31 May 2017, http://smr-project.eu.

[17] Centre for Research on the Epidemiology of Disasters (CRED), "The International Disaster Database," Accessed on: 31 May 2017 http://www.emdat.be/database

[18] A. Chandra et al., Building Community Resilience to Disaster. Santa Monica, CA, USA: RAND Health, 2011.

[19] T. Frankenberger, M. Mueller, T. Spangler, and S. Alexander, Community Resilience: Conceptual Framework 
and Measurement, Feed the Future Learning Agenda. Rockville, MD, USA: US Aid, 2013.

[20] International Federation of Red Cross and Red Crescent Societies, IFRC Framework for Community Resilience. Geneva, Switzerland: IFRC, 2014.

[21] A. Aitsi-Selmi and V. Murray, "Protecting the Health and Well-being of Populations from Disasters: Health and Health Care in The Sendai Framework for Disaster Risk Reduction 2015-2030," Prehospital and Disaster Medicine, Special Report, 2016, pp. 1-5.

[22] M. L. Birnbaum, E. K. Daily, A. O’Rourke, and A. Loretti, "Research and Evaluations of the Health Aspects of Disasters, Part I: Overview," Prehospital and Disaster Medicine, vol. 30, no. 5, 2015, pp. 512-522.

[23] T. J. Wilbanks, How Geographic Scale Matters in Seeking Community Resilience, CARRI Research Report 7. Oak Ridge, TN, USA: Oak Ridge National Laboratory, 2009.

[24] S. Pilemalm, R. Stenberg, and T. A. Granberg, "Emergency Response in Rural Areas," International Journal of Information Systems for Crisis Response and Management, vol. 5, no. 2, 2013, pp. 19-31.

[25] J. Da Silva, "City Resilience Framework," Ove Arup and Partners, London, UK, 2014.

[26] C. S. Renschler, A. E. Fraizer, L. A. Arendt, G.-P. Cimellaro, A. M. Reinhorn, and M. Bruneau, "A Framework for Defining and Measuring Resilience at the Community Scale: The PEOPLES Resilience Framework," US Department of Commerce, Gaithersburg, MD, USA, 2010.

[27] A. Sharifi, "A Critical Review of Selected Tools for Assessing Community Resilience," Ecological Indicators, vol. 69, pp. 629-647, 2016.

[28] A. Sharifi and Y. Yamagata, "On the Suitability of Assessment Tools for Guiding Communities Towards Disaster Resilience," International Journal of Disaster Risk Reduction, vol. 18, pp. 114-124, 2016.

[29] A. J. Imperiale and F. Vanclay, "Experiencing Local Community Resilience in Action: Learning from Postdisaster Communities," Journal of Rural Studies, vol. 47, no. 204-219, 2016.

[30] GOAL, "Toolkit for Measuring Community Disaster Resilience: Guidance Manual," European Community Humanitarian Office, Brussels, Belgium, 2015.

[31] O. Cohen, D. Leykin, M. Lahad, A. Goldberg, and L. Aharonson-Daniel, "The Conjoint Community Resiliency Assessment Measure as a Baseline for Profiling and Predicting Community Resilience for Emergencies," Technological Forecasting and Social Change, vol. 80, no. 9, pp. 1732-1741, 2013.

[32] Wikipedia, "Social Capital," Accessed on: 31 May 2017Available: https://en.wikipedia.org/wiki/Social_capital
[33] M. A. Pelling et al., "Social Learning and Resilience Building in the emBRACE Framework," European Commission, Brussels, Belgium, 2015.

[34] L. C. J. Mortelmans, J. Lievers, G. Dieltiens, and M. B. Sabbe, "Are Belgian Military Students in Medical Sciences Better Educated in Disaster Medicine than their Civilian Colleagues?," Journal of the Royal Army Medical Corps, vol. 162, pp. 383-386, 2016.

[35] J. Smith, M. J. Levy, E. B. Hsu, and J. L. Levy, "Disaster Curricula in Medical Education: Pilot Survey," Prehospital and Disaster Medicine, vol. 27, no. 5, pp. 492494, 2012.

[36] T. L. O’Sullivan, C. E. Kuziemsky, D. Toal-Sullivan, and W. Corneil, "Unraveling the Complexities of Disaster Management: A Framework for Critical Social Infrastructure to Promote Population Health and Resilience," Social Science and Medicine, vol. 93, pp. 238-246, 2013.

[37] P. Plough et al., "Building Community Disaster Resilience: Perspectives From a Large Urban County, ," American Journal of Public Health, vol. 103, no. 7, pp. 1190-1197, 2013.

[38] B. H. Morrow, "Community Resilience: A Social Justice Perspective, CARRI Research Report 4," Community and Regional Resilience Initiative, Oak Ridge, TN, USA, 2008.

[39] Wikipedia, "Disaster Risk Reduction," Accessed on: 31 May 2017 . Available: https://en.wikipedia.org/wiki/Disaster_risk_reduction

[40] M. L. Birnbaum, A. Loretti, E. K. Daily, and A. O’Rourke, "Research and Evaluations of the Health Aspects of Disasters, Part VIII: Risk, Risk Reduction, Risk Management, and Capacity Building," Prehospital and Disaster Medicine, vol. 31, no. 3, pp. 300-308, 2016.

[41] UNISDR, "Sendai Framework for Disaster Risk Reduction," Available: http://www.unisdr.org/we/coordinate/sendai-framework

[42] F. Demiroz and N. Kapucu, "The Role of Leadership in Managing Emergencies and Disasters," European Journal of Economic and Political Studies, vol. 5, 2012, pp. 91-101.

[43] C. Russo, "Emergency Communication Remains a Challenge Ten Years After 9//11," Available: http://www.homelandsecuritynewswire.com/emergencycommunication-remains-challenge-ten-years-after-911

[44] B. A. Turner, "The organizational and interorganizational development of disasters," Adm. Sci. Q., vol. 21, pp. 378-397, 1976.

[45] M. Turoff, "Organizational factors inhibiting the design of effective Emergency Management Information Systems (EMIS)," Proceedings of the Forty Fifth Annual Hawai'i 
International Conference on System Sciences (HICSS-45), Maui, HI, USA, 2012.

[46] C. Christensen, J. Grossman, and J. Hwang, The Innovator's Prescription: A Disruptive Solution for Health Care. New York, NY, USA: McGraw Hill, 2009.

[47] A. C. Norris, D. Singh, A. Palu, and D. T. Parry, "The Digital Disruption of Healthcare," Proceedings of the Proceedings of the Health Informatics New Zealand (HINZ) Annual Conference, Auckland, New Zealand, 2016.

[48] T. Spil and R. Klein, "The Personal Health Future," Health Policy Technology, vol. 4, no. 2, pp. 131-136, 2015.

[49] L. M. Vizer and A. Hall, "The Patient-Centered Electronic Health Record and Patient Portals," in Consumer Health Informatics: New Services Roles and Responsibilities, T. Wetter, Ed. Basel, Switzerland: Springer International Publishing, 2016, pp. 281-294.

[50] F. S. Collins and H. Varmus, "A New Initiative on Precision Medicine," New England Journal of Medicine, vol. 372, pp. 793-795, 2015.

[51] B. Meskó "RX Disruption: Technology Trends in Medicine and Health Care," The Futurist, vol. 48, no. 3, pp. 31-38, 2014.

[52] UNISDR, "Terminology on Disaster Risk Reduction," UN, Geneva, Switzerland, 2009.

[53] M. L. Birnbaum, E. K. Daily, A. O’Rourke, and A. Loretti, "Research and Evaluations of the Health Aspects of Disasters, Part II: The Disaster Health Conceptual Framework Revisited," Prehospital and Disaster Medicine, vol. 30, no. 5, pp. 523-538, 2015.

[54] M. L. Birnbaum, E. K. Daily, and A. O’Rourke, "Research and Evaluations of the Health Aspects of Disasters, Part III: Framework for the Temporal Phases of Disasters " Prehospital and Disaster Medicine, vol. 30, no. 6, pp. 628-632, 2015.

[55] M. L. Birnbaum, E. K. Daily, and A. O’Rourke, "Research and Evaluations of the Health Aspects of Disasters, Part IV: Framework for Societal Structures: The Societal Systems," Prehospital and Disaster Medicine, vol. 30, no. 5, pp. 633-647, 2015.

[56] M. L. Birnbaum, E. K. Daily, and A. O’Rourke, "Research and Evaluations of the Health Aspects of Disasters, Part V: Epidemiological Disaster Research," Prehospital and Disaster Medicine, vol. 30, 2015, pp. 648-656.

[57] M. L. Birnbaum, E. K. Daily, A. O’Rourke, and J. Kushner, "Research and Evaluations of the Health Aspects of Disasters, Part VI: Interventional Research and the Disaster Logic Model," Prehospital and Disaster Medicine, vol. 31, no. 2, 2016, pp. 181-194.

[58] M. L. Birnbaum, E. K. Daily, and A. O’Rourke, "Research and Evaluations of the Health Aspects of Disasters,
Part VII: The Relief/Recovery Framework," Prehospital and Disaster Medicine, vol. 31, 2016, pp. 195-210.

[59] M. L. Birnbaum, E. K. Daily, and A. O’Rourke, "Research and Evaluations of the Health Aspects of Disasters, Part IX: Risk-Reduction Framework," Prehospital and Disaster Medicine, vol. 31, 2016, pp. 309-325.

[60] E. Topol, The Creative Destruction of Medicine. New York, NY, USA: Basic Books, 2012.

[61] S. Martinez, S. Berkås, and R. Fensli, "Agder Living Lab: Co-creation of Inclusive Health Solutions for and with Citizens," International Journal of Integrated Care, vol. 16, no. 5, 2016, pp. 1-2.

[62] European Union, "Using the Quadruple Helix Approach to Accelerate the Transfer of Research and Innovation Results to Regional Growth," EU, Brussels , Belgium, 2016.

[63] A. Abdelgawad, J. Radianti, M. Snaprud, and J. Krogstie, "Experimentation with a System Dynamics Based Interactive Learning Environment: A Case Study of Accessibility of Norwegian Municipalities Websites," International $J$ Simulation: Systems, Science and Technology, vol. 17, no. 35, 2016, p. 11. 